\title{
Color Arrangement in the Pastoral Style Fashion Design
}

\author{
Li Wan \\ Huanghe Science and Technology College \\ Zhengzhou, Henan, China
}

\begin{abstract}
Since the 21st century, the pastoral style which became popular among fashion circle is a starting point of this thesis. I studied color arrangement of pastoral style fashion and tried to find regular artistic characteristics and development trend, hoping draw conclusions to guide their daily look, guide designers to better carry for the fashion style design, and also hope these content can guide people's daily dress and enhance the dress collocation theory value.
\end{abstract}

\section{Keywords—patrol style; color arrangement; characteristic}

\section{INTRODUCTION}

Clothing is one of the material conditions for human beings to survive, and it is also an important spiritual element in the social production activities. In the formation highly developed today, with significant changes in the improvement of people's cultural level, the material life and ideology, a lot of people will not only meet the physiological function of clothing in the pursuit of fashion, but more strongly pursue the beauty of the era in the clothing contains (popular beauty), the beauty of wisdom (beauty and dress collocation) after giving the wearer's spirit. More and more people desire to express self consciousness and spirit to society through their own clothing collocation. Therefore, under the impact of psychology, style of clothing has become one of the important forms of clothing collocation. "The so-called clothing style, that is, constitution of the dress image of all the elements to form a unified and charming appearance with a distinct tendency."[1] With the growing personalized dress, more and more full of characteristics of the clothing style emerge in an endless stream, such as the well-known neutral wind, retro, Lolita, OL, or even hip-hop, punk fashion in clothing collocation of the carrier are blooming with the unique style of charm to exhibit strong post modernist fashion. While pastoral style of clothing is unique. Its unique fresh style and natural taste of getting back to basics become increasing city people's choice of dress, and has become a very personality tendency of costume design in a style. So I take the pastoral style of clothing color collocation as the breakthrough point to study the art characteristics and development trends of dress collocation, hoping to find spiritual pursuit and guiding significance of artistic theory from this kind of clothing style.

The beauty of clothing is the comprehensive embodiment of color, shape and material, and three is indispensable. But the first thing that catches people's eyes is the color of clothing. Different hue, lightness and purity showing in the clothing can express different feelings and moods and bring people rich visual and psychological feelings. So color is a very important factor in the design of clothing. In the process of rural style clothing design, color harmony is one of the important factors that can reflect the overall effect of clothing. The appropriate color design effect will not only strengthen the original color characteristics and clothing characteristics, but also reflects the spirit of the wearer, and even the characteristics of the times, resulting in the psychological effect of clothing itself.

Pastoral style of clothing color has prominent features, some are wide selection of colors, creating the atmosphere of birds twitter and fragrance of flowers; and some are simple but elegant tranquil to express the quiet and empty countryside. So we must grasp all the color of the characteristics of pastoral style clothing, only after understanding these features, we can tease out the applicable clothing color arrangement principle, otherwise easily blend with other styles of clothing color, leading to mix in arrangement and not clearly showing the pastoral style unique spirit of artistic conception.

\section{The Color Characteristics of Pastoral Style Clothing}

Before the color arrangement of pastoral style clothing, we must first analyze the color characteristics of the style. Under the full understanding of the characteristics of its color, we can correctly carry out the color, not simply in order to color to affect its style effect.

Count the current popular pastoral style clothing, which is divided into two aspects. One is dominated by American pastoral "flower" that is a variety of sizes of printing patterns as the main form of "rural" pastoral style clothing, such clothing color are gorgeous, lightness and high purity, floral prints seeming no tricks, but it does not mean that can set flowers in a cloth body in the arrangement. For example D\&G2011 spring releases many floral sprints, but each piece of clothing subject color not more than three, that is to say that you can wear a flower suits, trousers and pack headscarves, and print flower where you have never expected piece, but the overall color cannot spread. Color blocking is not a problem, which is better and better to be more intense, the use of color characteristics of pastoral style of clothing color layout has become a greater tendency to the clothing effect, which are filled with bright and delicate visual perception "Fig. 1" and "Fig. 2". 


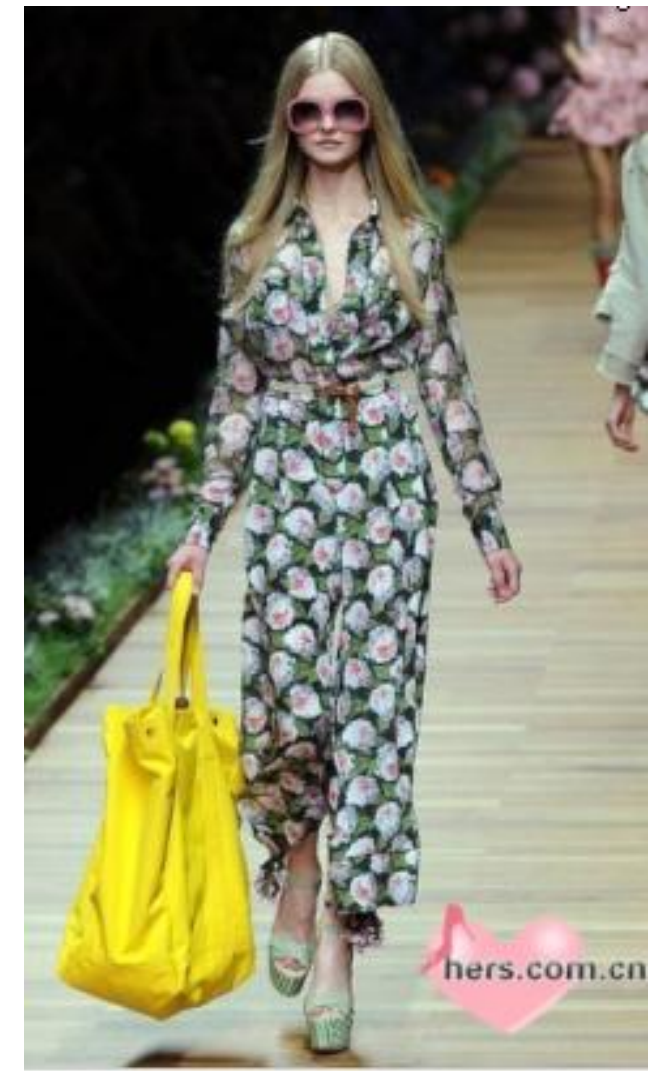

Fig. 1. "Rural" pastoral style clothing

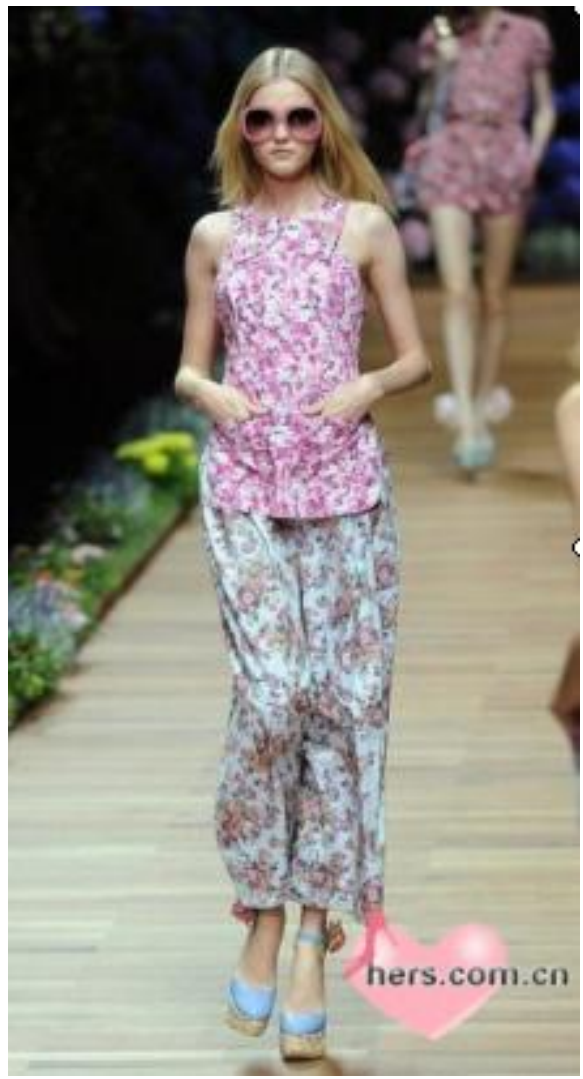

Fig. 2. "Rural" pastoral style clothing
The other is "pattern" under the influence of English country, namely, with a simple plaid and striped lines combination as the main form to create a strong "Holiday Garden" style of the clothing. The clothing color is simple and elegant, the style is loose or close with nature, sometimes, with some broken decoration. We will regard cotton, hemp and other natural fabric as the main material. The fringe pattern and combination of lines, a sense of the level of the lace decoration, exquisite lace or figurative, abstract geometric patterns are typical characteristics of such pastoral style clothing. The artistic conception not only revealed the spiritual demands of people eager to return to nature, but showed a strong romantic color, so it will give a person with calm, quiet and rustic charm. The carefree and content of "Holiday Garden" clothing will also tend to various geometric patterns and elegant tone floral pattern making industry simple and unique, even the simple style is full of the vigor and vitality of the nature. This is the charm of the pastoral style of the holiday, plain and simple, alone in the quiet charm.

Such as Louis Vuitton, this season's theme is through a mix of clothing stripes and plaid to show full of fascinating idyllic atmosphere, and the main inspiration often comes from the countryside scenery, blue sky, bright sunshine and gentle breeze, etc., all this bringing people endless imagination as if return to the embrace of the wilderness. Clothing color is wandering in camel white, earth color, khaki and light blue "Fig. 3", "Fig. 4". This kind of clothing mainly through the geometric fringe stitching reduces the brightness to express the relaxed and comfortable visual effect.

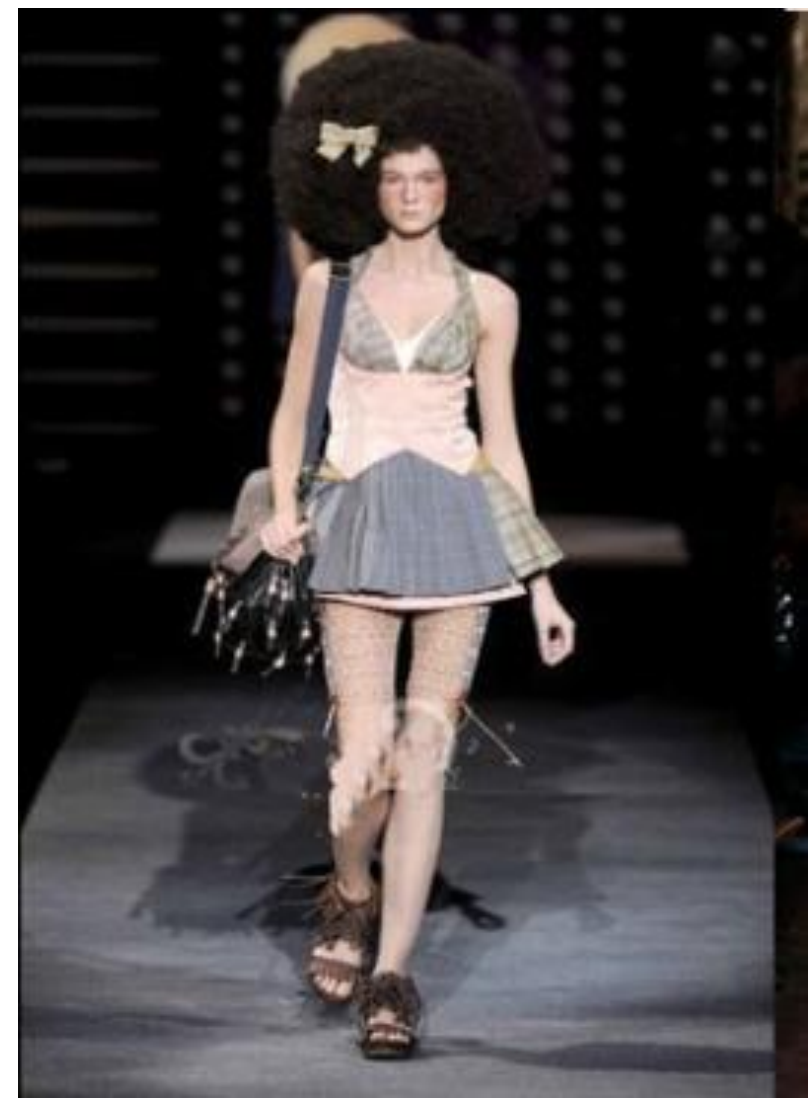

Fig. 3. "Holiday Garden" style of the clothing 


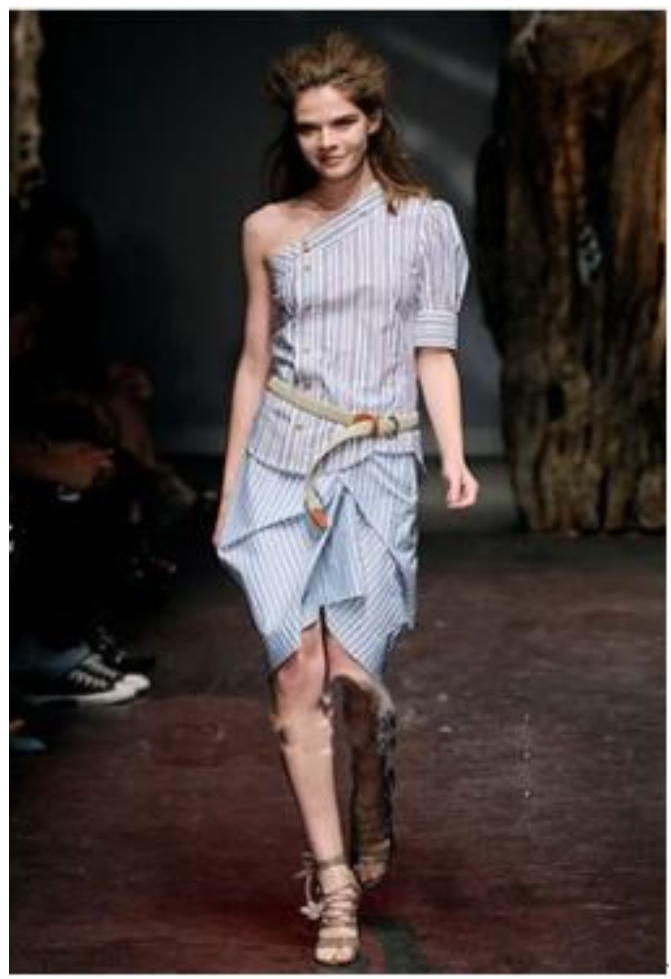

Fig. 4. "Holiday Garden" style of the clothing

\section{COlOR ARRAngement of PAStORAL StYle Clothing}

Color arrangement in clothes is also known as the color blending or color layout. Master its principle of color and layout can make it play its biggest aesthetic effect in the dress. Principle can make color in the dress to play its biggest aesthetic effect. How to carry on the color arrangement in the pastoral style clothing is the key point of this chapter. By comparing the current popular style of pastoral style clothing, we found that the pastoral style clothing in the color arrangement mainly has following forms:

\section{A. No Color Aarrangement}

No color arrangement is colorless that is composed of black, white and gray. We often say that just wear black and white if you do not have fashion sense. Because of a steady tone of black, white and gray, it has strong visual sense of acceptance and not produces an obtrusive color conflict, belonging to the relatively simple arrangement principle. No color arrangement is often used in the British pastoral style of clothing to create and elegant and easy visual effect and be suitable for the vast majority of people in the daily life. The picture below is classic black and white plaid skirt with $\mathrm{V}$ neck pleated middle sleeve, this is typical pastoral style clothing without color collocation. Contrast harmony of black and white produce harmonious visual perception, feeling that along with the nature to form a tranquil and natural beauty, glancing simple and comfortable mood performance. "Fig. 5"

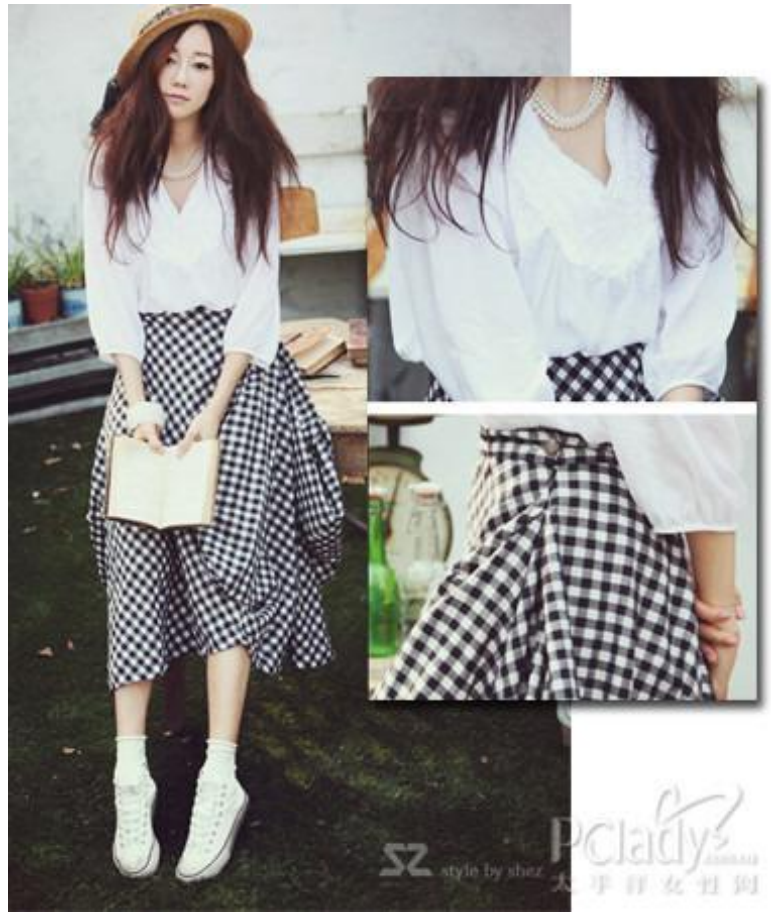

Fig. 5. No Color Aarrangement

\section{B. Non-Color Arrangement}

Non-color arrangement is that choose any one of the color with black, white and gray. This color can often produce a striking visual effect for dress collocation to make the finishing point. For color arrangement of pastoral style, we also often choose this collocation principle to play both eye-catching and soothing effect. For example, red with black can produce strong visual effect, giving warm and elegant feeling. Below the sling floral print dress is typical arrangement of black and red, mixing together classic black and bright red pattern to show quite new sense of charm "Fig. 6"; while blue and white collocation gives people sober, refined elegant and natural feeling. Below the deep blue finely floral pattern which has a pastoral sense collocates chest pleated no shirt sleeve, with a wide waist belt to lengthen the stature to look tall and slender, adding a little fresh and pleasant pastoral style "Fig. 7". Through the example, we can see non-color arrangement in the color collocation of pastoral style clothing also can be popular to show specific sense of the effect, of course, in the general case, in non- color collocation, we should be sure to pay attention to tall lightness with white, medium lightness with gray and tall lightness with black. The visual effect of this color arrangement will be harmonious. 


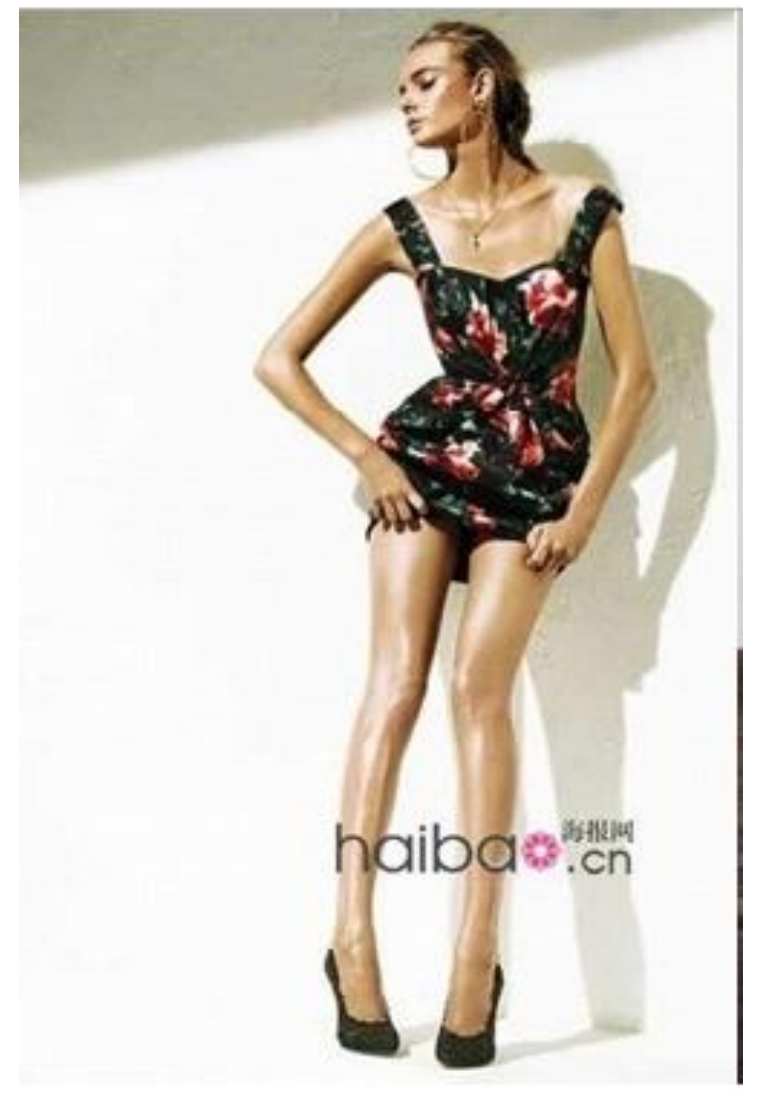

Fig. 6. Non-color arrangement

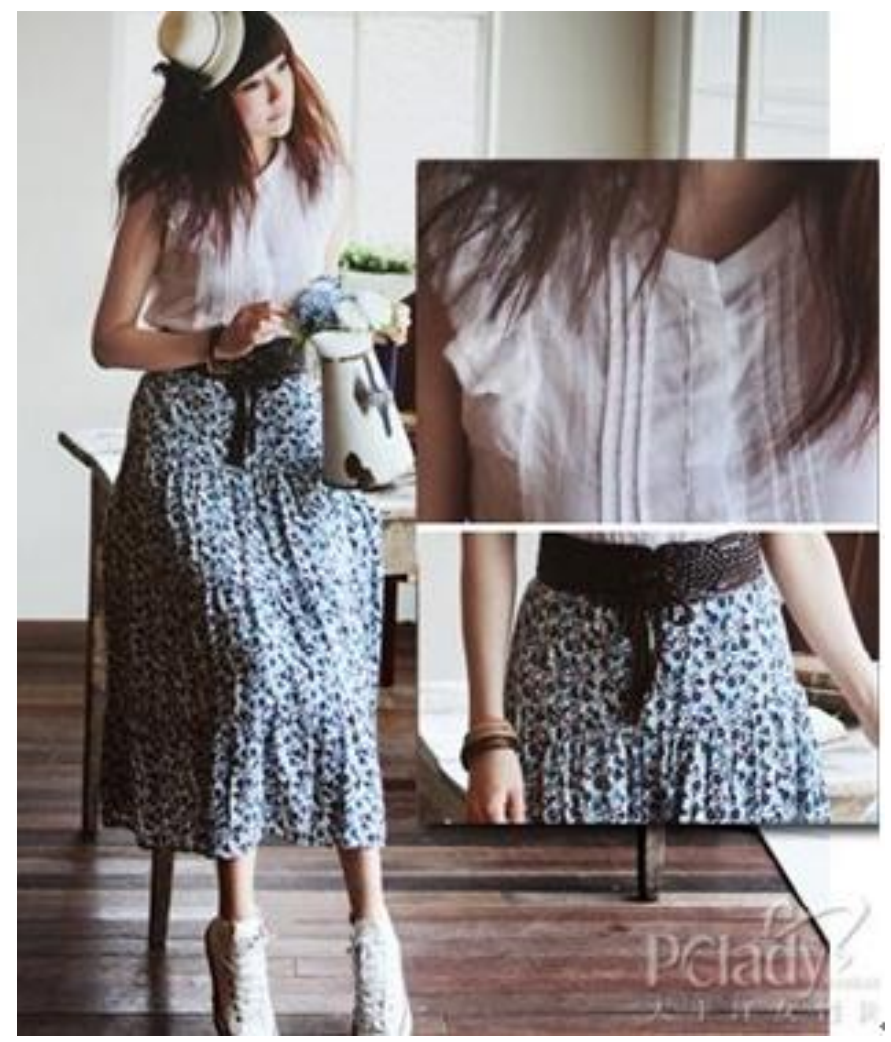

Fig. 7. Non-color arrangement

\section{Similar Color Arrangement}

The difference in hue angle of color ring is based on uniform hue tone. So the so-called similar color is the adjacent color within the color ring of about 90 degrees. With similar colors to match the dress, you can get a harmonious unity of the overall effect and can create a youthful positive color character. This feature is very consistent with the pastoral style of clothing in rural areas, and is very popular with women, especially young women. Therefore a lot of pastoral styles of clothing also take the principle of similar color arrangement to highlight its style of youth breath. This kind of color arrangement form often adds the style of the dress.

For example, below this piece of printing one-piece bubble shorts use similar color collocation of bright yellow and red, but significantly decrease the purity of yellow and red to express lively and playful feeling with elegant color, fully feeling relax and comfortable pastoral style clothing, at the same time, color coordination collocation makes the visual effect of the whole fresh and natural garment "Fig. 8". On the right side of this picture is bubble shorts collocation print dress, the suit of color is very harmonious that green and purple are in the interphase without conflicts through the repeated appearance in different parts of the color association technique, showing the overall effect of being dedicate but not vulgar, smart and sweet "Fig. 9".

The arrangement of similar colors in the actual operation must pay attention to the number of colors appear in the body not too much, otherwise the other colors will affect or cover the visual effect of similar color harmony.

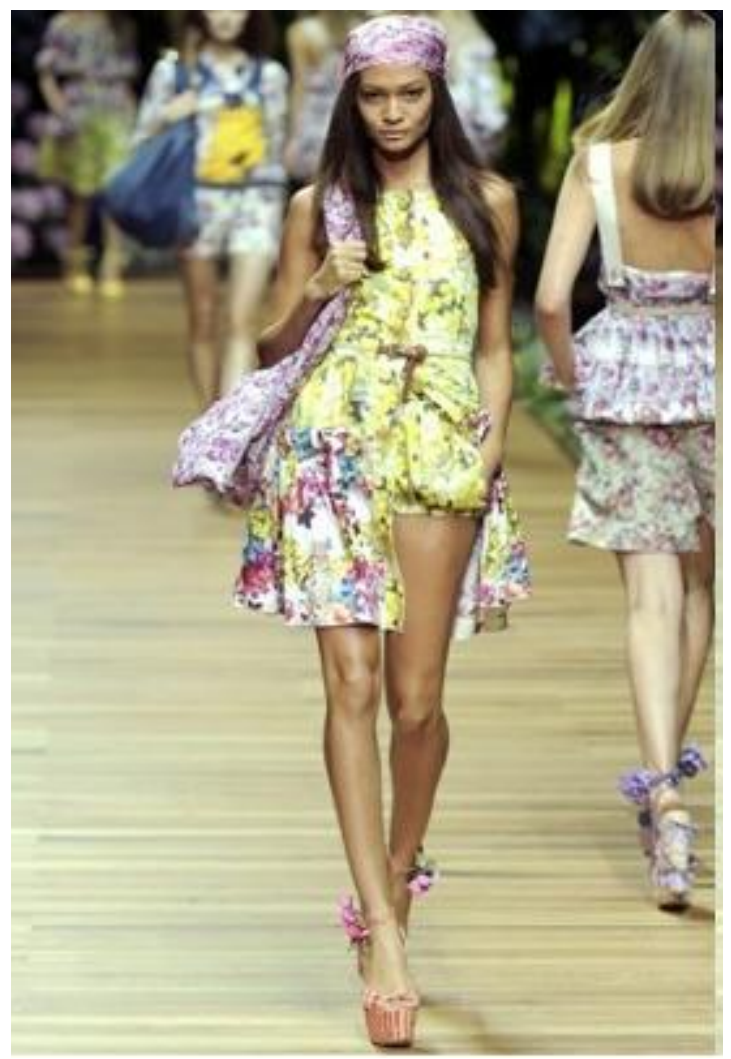

Fig. 8. Similar color arrangement 


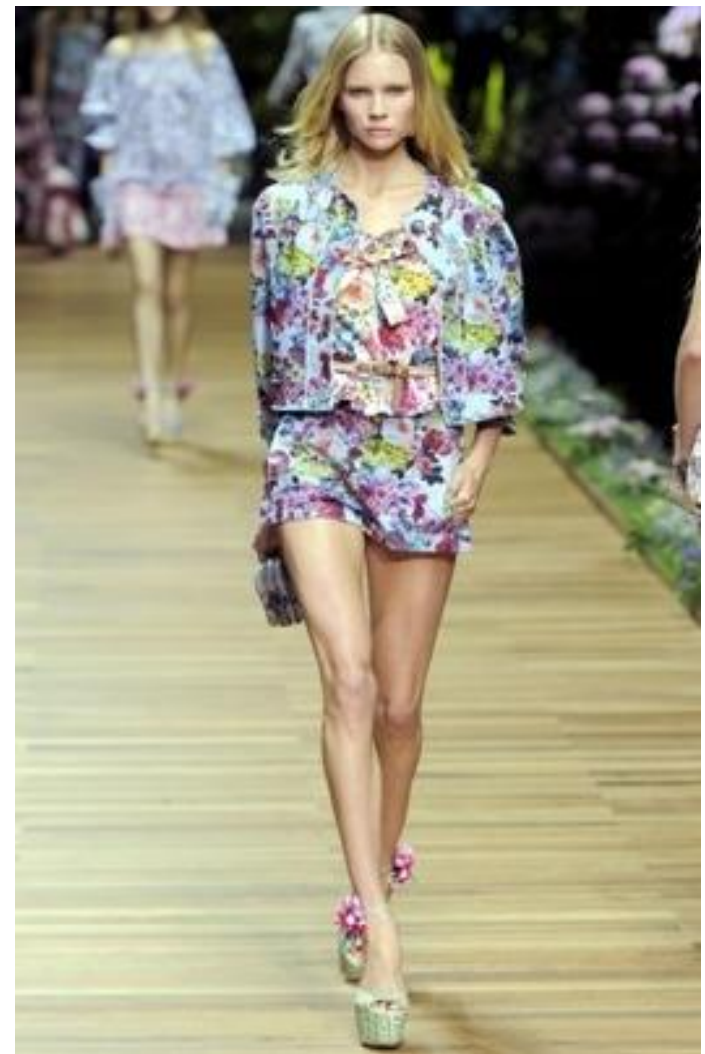

Fig. 9. Similar color arrangement

\section{Complementary Color Arrangement}

Complementary color arrangement refers to the two relative colors, which is the color contrast. The use of complementary colors can produce lively, jumping, gorgeous or light sense, which is preferred color principle for "flower" pastoral style clothing, but when we choose the complementary colors, we must determine a dominant role of color based. Main color should be consistent with the whole set of clothing tone, the main color in the entire clothing should be accounted for the vast majority of the proportion of the area or occupy more important position. . Auxiliary color also must conform to the overall tone of the clothing, such as red and green, yellow and purple. Complementary color arrangement in the clothing forms a bright contrast, especially in the pastoral style clothing, and many prints are in bold use of complementary color to increase the visual effect of clothing to add clothing strong visual aesthetic.

Complementary color clothing below mainly expresses on the pattern, high lightness of green foiling brilliant pink roses, though red and green mix to be quite eye-catching, express the simple and comfortable feel of pastoral style at a glance, looking pure, fresh and natural under the white color collocation as if placed in the clothing "Fig. 10". Many rural style clothing are relying on this intense color collocation to reflect local flavor, being memorable.

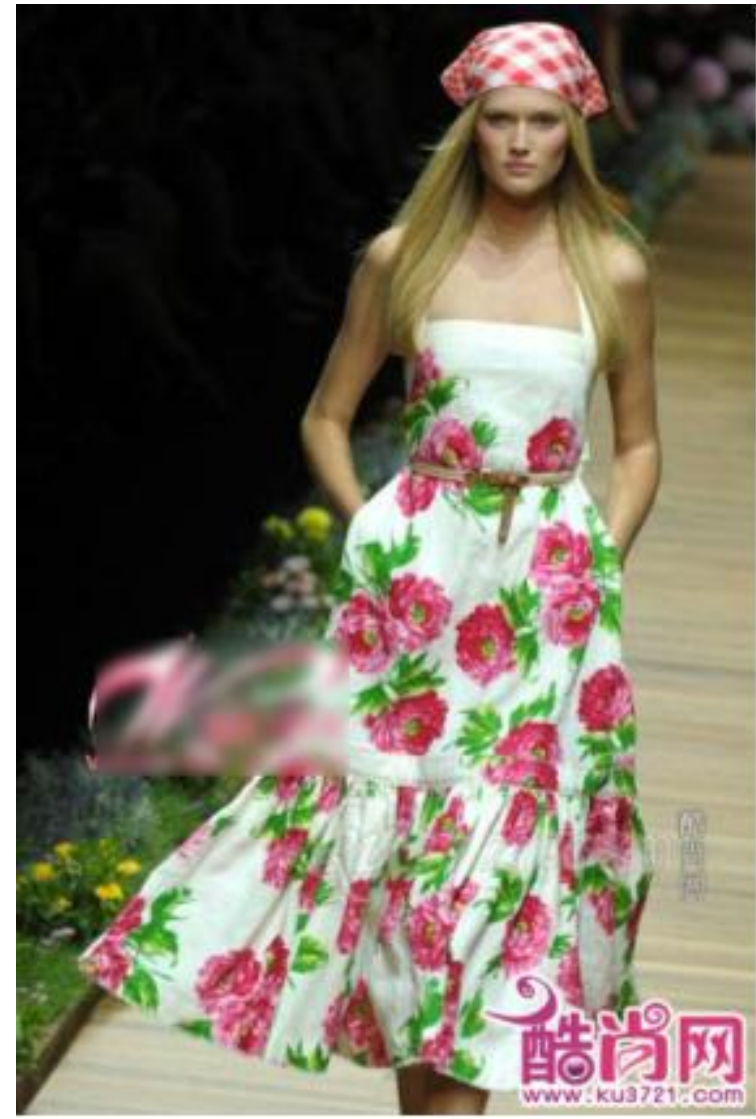

Fig. 10. Complementary color arrangement

Overall, the visual effect of clothing must be combined with color, shape and quality, so as to form a comprehensive image of beauty of clothing. Whether in color, texture or pattern, all kinds of elements of clothing beauty form must be unified in a form of style. If the style is different, even each element itself is beautiful, and it is difficult to achieve a comprehensive image of the beauty of harmony. Color is often the first impression for clothing. Therefore, in the design of clothing, we must first consider the general tone of the clothing and also pay attention to the tone of the mix.

Pastoral style of clothing due to its unique temperament in design with particular attention to the details of the form of beauty, its color, style and fabric should emphasize "regression" feeling that is simple shape and intrinsic long literary and artistic feeling. It is not necessary to be dyed full of poetic beauty in design, but must fade urban traces to express the free feeling of people in the world, in a field covered with wild flowers and weeds, plenty of sunshine, fresh air, quiet forest, clear streams, and without roar of machine, no air pollution, no hustle and bustle of the city, which is away from the tired of living in a quiet environment. This is the spirit of the garden style clothing design. This design idea and spirit are well versed in to achieve the success of the design.

\section{REFERENCES}

[1] Wang Yuan. "The Art of Wearing Apparel Arrangement", p.138, China Textile Press,2009. 